\title{
Soft Tissue Profile Response in Adult Orthodontic Patients following Extractions
}

\author{
Mandeep Bhullar ${ }^{1} \quad$ Amita Badhan ${ }^{1}$ Sanjay Mittal ${ }^{1}$ \\ ${ }^{1}$ Department of Orthodontics and Dentofacial Orthopedics, Bhojia \\ Dental College, Baddi, Himachal Pradesh, India
}

\author{
Isha Aggarwal' Divya Singla' Merry Goyal'
}

Dent J Adv Stud 2019;7:74-80

\begin{abstract}
Address for correspondence Amita Badhan, Department of Orthodontics and Dentofacial Orthopedics, Bhojia Dental College, Baddi, Himachal Pradesh 173205, India (e-mail: bd.amita06@gmail.com).
\end{abstract}

\begin{abstract}
Keywords

- incisor retraction

- soft tissue changes

- facial profile
\end{abstract}

Introduction The position of the incisors is considered as a key landmark in treatment planning to provide the patient with the most attractive and well-balanced smile. It is important to quantify the relationship between anteroposterior position of incisors to overlying soft tissue structures.

Aim The purpose of this study was to evaluate cephalometric changes on the soft tissue profile of the adult patients after first premolar extraction.

Materials and Methods The study included pretreatment and posttreatment lateral cephalograms of 24 adult patients (Class II div 1 malocclusion and Class I bimaxillary protrusion) treated with preadjusted edgewise appliance following first premolar extractions. Seven angular and twelve linear soft tissue parameters were evaluated. Six hard tissue parameters were evaluated.

Results All the linear and angular measurements pertaining to soft tissue and hard tissue showed significant changes. When posttreatment values were compared with pretreatment values, certain parameters (nasolabial angle, $Z$ angle, UL and LL length, and UL strain) were found to be increased, whereas other parameters showed decrease in their posttreatment values. The tissue alteration showed statistically significant increase in nasolabial angle, $Z$ angle, and decrease in soft tissue profile and interlabial gap.

Conclusion Facial profile improvement can be enhanced by dentoalveolar and soft tissue retraction following premolar extraction.

\section{Introduction}

A thing of beauty is a joy forever. This is a common saying, but beauty is something which gives the highest degree of pleasure to the mind and suggests that object of delight approximates to one's conception. ${ }^{1}$ Facial attractiveness and dental esthetics have been shown to have a significant impact on the social status and quality of life. Achieving an esthetic smile has been shown to be one of the most important reasons why patients request orthodontic treatment. ${ }^{2}$

The position of the incisors is considered as a key landmark in treatment planning to provide the patient with the most attractive and well-balanced smile. ${ }^{3}$ The profile form of the patient face is often representative of the inclination of anterior teeth, ${ }^{4}$ and clinicians should align incisor

received

July 24, 2019

accepted

July 30, 2019

published online

October 18, 2019 positions ideally to obtain good facial balance following treatment taking into consideration the great variability in soft tissue thickness between individuals. ${ }^{5}$ Therefore, it is important to quantify the relationship between anteroposterior position of incisors to overlying soft tissue structures. Tweed emphasized balance of the facial profile as the first priority in orthodontic treatment. The $\mathrm{Z}$ angle introduced by Merrifield, the $\mathrm{H}$ line by Holdaway, and the Ls'Li' line by Imajyo is also used to evaluate a person's soft tissue profile. However, these evaluations are only anteroposterior measurements of the distance between the most forward point on the upper and lower lips and the setting of reference line. Arnett et $\mathrm{al}^{6}$ introduced soft tissue cephalometric analysis, which includes soft tissue measurements of the midface area aimed at objectively evaluating facial harmony and balance. ${ }^{7}$
License terms

(요 (1) $\odot \circledast$ 
Orthodontists have long recognized that the extraction of premolars often is accompanied by changes in the soft tissue profile. At times, these changes result in substantial improvements in the profile and frequently justify the extraction of teeth in patients without other indications. At other times, however, premolar extraction can lead to a flatter profile. ${ }^{8}$

\section{Aim}

The main aim of this article is to evaluate the cephalometric changes occurring in the soft tissue profile of adult patients who underwent orthodontic treatment following first premolar extractions.

\section{Materials and Methods}

This study is a retrospective study conducted on 24 pre- and posttreatment lateral cephalograms of the patients selected from the archives of the Department of Bhojia Dental College and Hospital, Bhud, Solan, Himachal Pradesh. The patients were selected on the basis of following criteria:

1. Good soft and hard tissue outline visible on the radiographs.

2. Adult patients having Class I bimaxillary protrusion and Class II div 1 malocclusion treated with preadjusted edgewise appliance following first premolar extractions.

3. No craniofacial abnormality, no gingival recession, no missing or supernumerary teeth, and no grossly carious teeth.

4. Age of the patient should range between 15 and 25 years.

Pre- and posttreatment lateral cephalograms were obtained with the Frankfort horizontal (FH) plane parallel to the floor, lips in relaxed position, and teeth in maximum intercuspation. All the cephalograms were traced manually by the same investigator. They were hand traced onto 0.003 inch matte acetate paper. All the landmarks were identified and marked.

\section{Cephalometric Landmarks}

Description of various cephalometric landmarks used in the

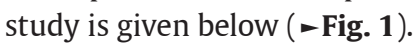

\section{Soft Tissue Landmarks ${ }^{9}$}

1. Glabella (G): The most prominent anterior point in the midsagittal plane of the forehead.

2. Soft tissue nasion ( $\left.\mathbf{N}^{\prime}\right)$ : The point of greatest concavity in the midline between the forehead and the nose.

3. Pronasale (P): The most prominent or anterior point of the nose (tip of the nose).

4. Subnasale (Sn): The point at which the columella merges with the upper lip in the midsagittal plane.

5. Labrale superius (Ls): A point indicating the mucocutaneous border of the upper lip.

6. Stomion superius (Stms): The lower most point on the vermilion of the upper lip.

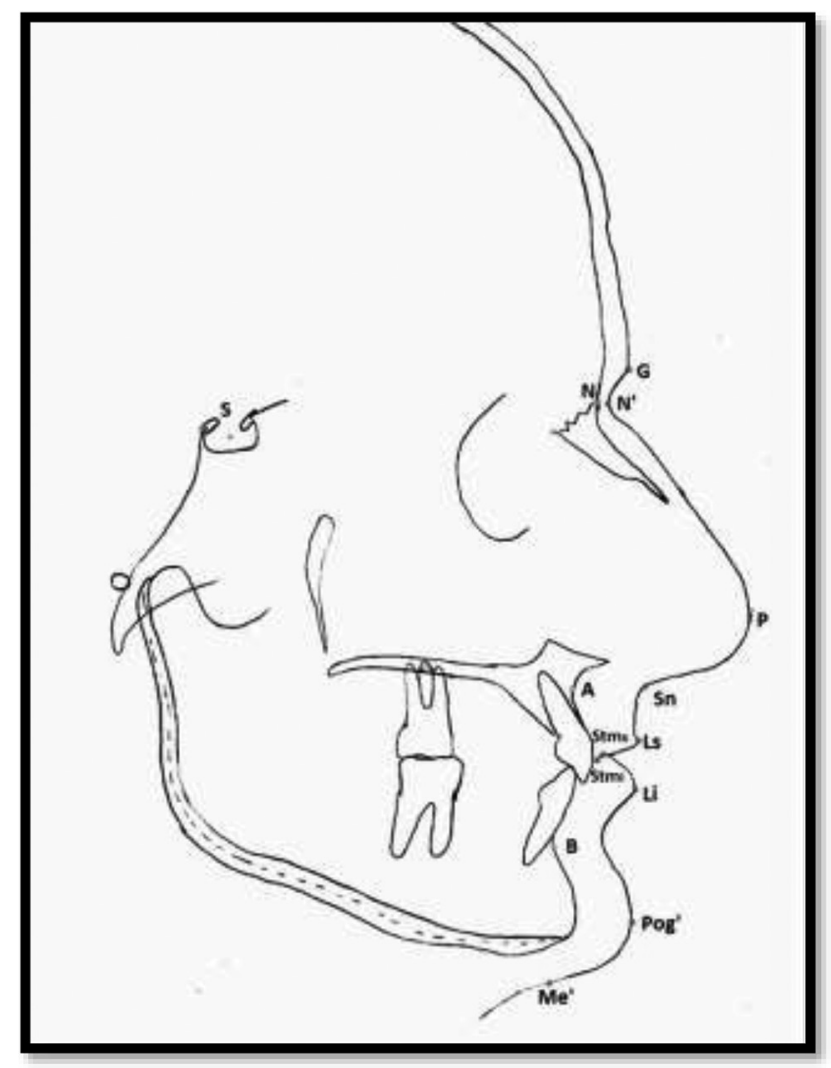

Fig. 1 Landmarks used in the study.

7. Stomion inferius (Stmi): The upper most point on the vermilion of the lower lip.

8. Labrale inferius (Li): The median point in the lower margin of the lower membranous lip.

9. Soft tissue pogonion (Pog'): The most anterior or prominent point on the chin in the midsagittal plane.

10. Soft tissue menton (Me'): Lowest point on the contour of the soft tissue chin.

\section{Hard Tissue Landmarks ${ }^{9}$}

1. Sella (S): Center of the pituitary fossa of the sphenoid bone.

2. Nasion (N): The most anterior point on the frontonasal suture in the midsagittal plane.

3. Point A (A): The most posterior midline point in the concavity between the anterior nasal spine and the prosthion.

4. Point B (B): The most posterior midline point in the concavity of the mandible between infradentale and pogonion.

\section{Soft Tissue Angular Parameters}

Description of soft tissue angular parameters used in the

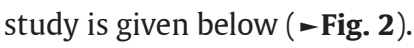

1. NLA: Angle between a line tangent to the base of the nose and a line tangent to the upper lip. ${ }^{10}$

2. H angle: Angle between $\mathrm{H}$ line and $\mathrm{Na}^{\prime}-\mathrm{Pog}^{\prime}$ line. ${ }^{10}$

3. Z angle: Angle between FH plane and a profile line formed by touching the chin and the most procumbent lip. ${ }^{10}$

4. Soft tissue profile: Angle formed by soft tissue nasion-subnasion-soft tissue pogonion (N'-Sn-Pog'). ${ }^{10}$

5. Facial angle: Inferior inside angle in which N'-Pog' line intersects with $\mathrm{FH}$ plane. ${ }^{10}$ 
6. Mentocervical angle: Intersection of $\mathrm{E}$ line and tangent to the submental area. ${ }^{9}$

7. Upper lip angle: Angle formed by the intersection of Sn-Ls and FH perpendicular passing through $\mathrm{Sn} .{ }^{10}$

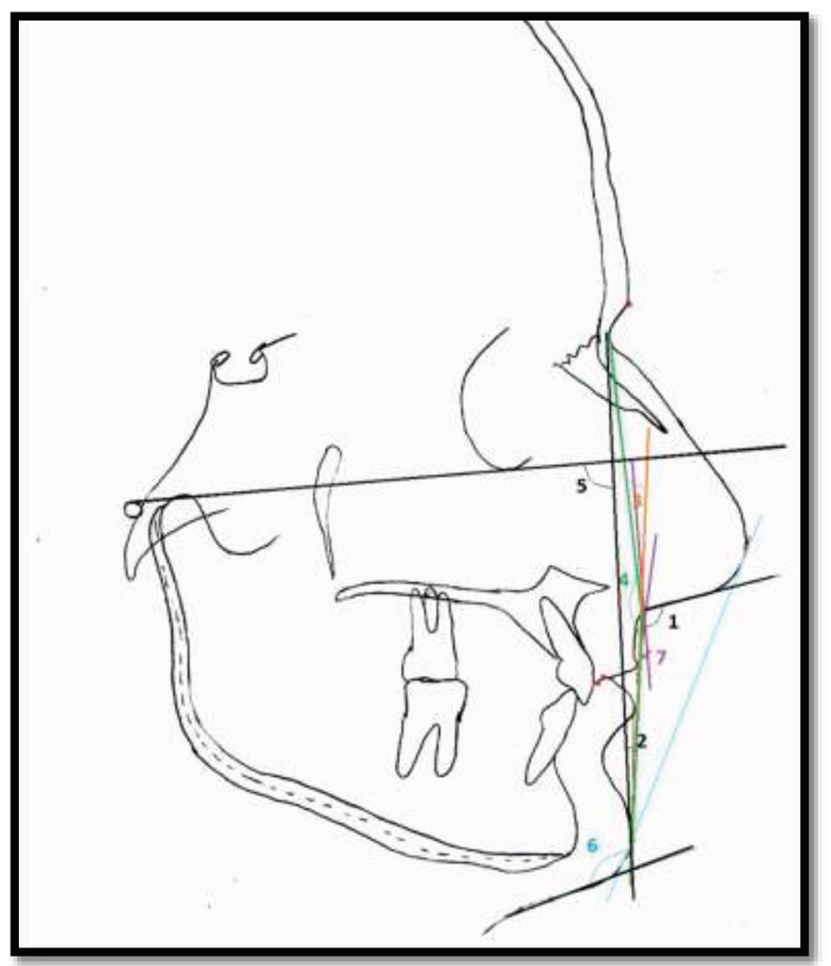

Fig. 2 Soft tissue angular parameters used in the study $(1=$ nasolabial angle [NLA], $2=\mathrm{H}$ angle, $3=\mathrm{Z}$ angle, $4=$ soft tissue profile, 5 = facial angle, 6 = Mentocervical angle, and $7=$ upper lip angle).

\section{Soft Tissue Linear Parameters}

Description of soft tissue linear parameters used in the study is given below ( $\mathbf{- F i g . ~} \mathbf{3 A}$ and $\mathbf{B}$ ).

1. Upper lip prominence: Perpendicular distance from labrale superioris to the line extending from the subnasale to soft tissue pogonion. ${ }^{10}$

2. Lower lip prominence: Perpendicular distance from labrale inferioris to the line extending from the subnasale to soft tissue pogonion. ${ }^{10}$

3. Upper lip length: Vertical distance from subnasale to Sts. ${ }^{10}$

4. Lower lip length: Vertical distance from Sti to soft tissue menton. ${ }^{10}$

5. E line to upper lip: Horizontal distance from $\mathrm{E}$ line (line connecting tip of nose and soft tissue chin) to upper lip anterior. ${ }^{10}$

6. E line to lower lip: Horizontal distance from $\mathrm{E}$ line to lower lip anterior. ${ }^{10}$

7. Interlabial gap: Sts-Sti distance measured parallel to nasion perpendicular. ${ }^{10}$

8. Superior sulcus depth: Horizontal distance measured to a perpendicular to $\mathrm{FH}$ plane and tangent to the vermilion border to the upper lip. ${ }^{10}$

9. Upper lip thickness: Horizontal distance between upper lip anterior and the base of the alveolar process, measured $3 \mathrm{~mm}$ below point A. ${ }^{10}$

10. Upper lip strain: Horizontal distance from vermilion border of the upper lip to labial surface of the crown of most proclined maxillary incisor. ${ }^{10}$

11. Lower sulcus depth: Point of greatest incurvation between the vermillion border of the lower lip and the soft tissue chin and is measured to the H line. ${ }^{9}$
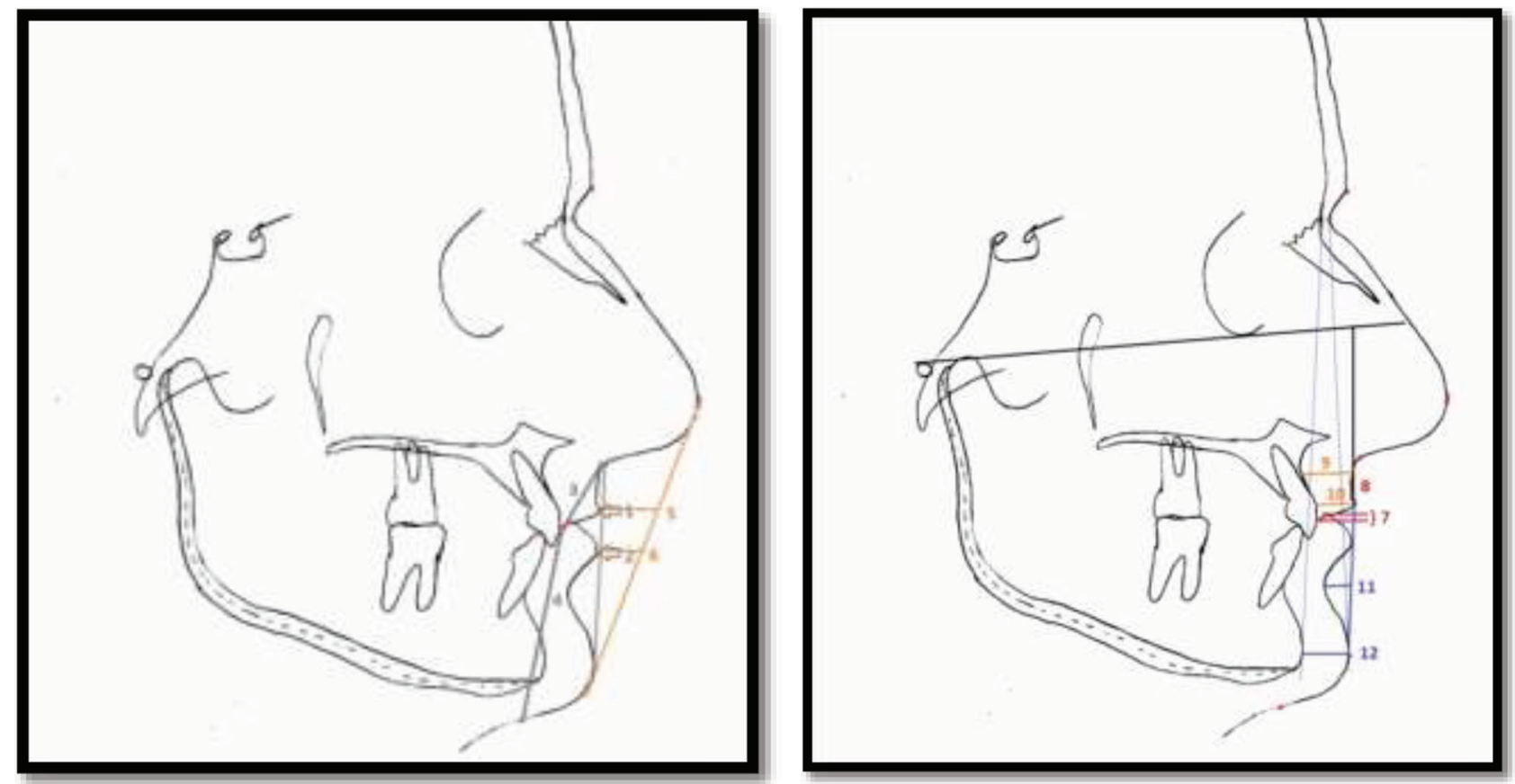

Fig. 3 (A) Soft tissue linear parameters used in the study ( $1=$ upper lip prominence, $2=$ lower lip prominence, $3=$ upper lip length, $4=$ lower lip length, $5=\mathrm{E}$ line to upper lip, and $6=\mathrm{E}$ line to lower lip). (B) Soft tissue linear parameters used in the study $(7=$ interlabial gap, $8=$ superior sulcus depth, 9 = upper lip thickness, 10 = upper lip strain, 11 = lower sulcus depth, and 12 = soft tissue chin thickness). 
12. Soft tissue chin thickness: Distance between two vertical lines representing hard tissue and soft tissue facial planes at the level of Ricketts' suprapogonion. ${ }^{10}$

\section{Hard Tissue Parameters}

Description of hard tissue parameters used in the study is given below ( Fig. 4$)^{10}$

1. UI-SN: Angulation of the long axis of U1 to S-N plane.

2. UI-NA in degrees: Angulation of the long axis of U1 to NA line.

3. UI-NA in mms: Horizontal distance from Is and line connecting hard tissue $\mathrm{N}$ to hard tissue point $\mathrm{A}$.

4. IMPA: Angulation of long axis of L1 to mandibular plane.

5. LI-NB in degrees: Angulation of the long axis of L1 to NB line.

6. LI-NB in mms: Horizontal distance from Ii and line connecting hard tissue $\mathrm{N}$ to hard tissue point $\mathrm{B}$.

The angular and linear parameters were evaluated for the pre- and posttreatment cephalograms. The values so obtained were subjected to statistical analysis.

\section{Statistical Analysis}

All the statistical analysis was performed using SPSS statistical package. The mean and standard deviations were calculated. The differences between the pre- and posttreatment results for each parameter were determined and subjected to paired $t$-test. The level of significance was set at $p<0.05$. The correlation between soft tissue changes and the hard tissue (incisor) changes was calculated using Pearson's correlation coefficient.

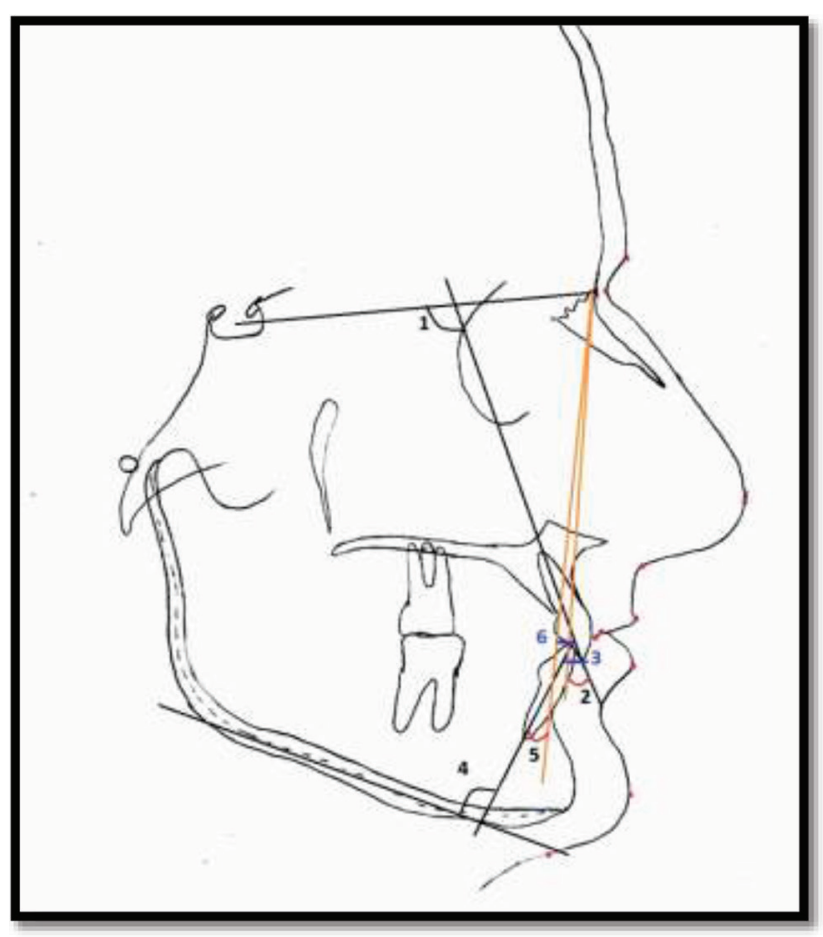

Fig. 4 Hard tissue angular and linear parameters used in the study $(1=\mathrm{UI}-\mathrm{SN}, 2$ = UI-NA in degrees, $3=\mathrm{UI}-\mathrm{NA}$ in $\mathrm{mms}, 4=\mathrm{IMPA}, 5=\mathrm{LI}-\mathrm{NB}$ in degrees, and $6=\mathrm{LI}-\mathrm{NB}$ in $\mathrm{mms}$ ).

\section{Results}

The descriptive statistics of soft tissue cephalometric parameters in pre- and posttreatment results showed that means of certain parameters (nasolabial angle [NLA], Z angle, upper lip and lower lip length, and upper lip strain) were found out to be increased, whereas other parameters showed decrease in their posttreatment values. The means of the parameters when analyzed by comparing between pre- and posttreatment results showed that certain soft tissue parameters (NLA, $\mathrm{H}$ angle, $\mathrm{Z}$ angle, upper lip-angle, upper lip and lower lip prominence, upper lip and lower lip length, E line to upper lip and lower lip, interlabial gap, superior sulcus depth, upper lip strain, and soft tissue chin thickness) were found to be statistically significant $(p<0.05)$ as depicted in - Table 1 .

On the upper and lower dentoalveolar components, all parameters related to the maxillary and mandibular incisors showed statistically significant alterations $(p<0.5)$.

There was a strong positive correlation between the soft tissue changes following upper and lower incisors retraction as depicted in - Table $\mathbf{2}$. There was a statistically significant increase in NLA and decrease in soft tissue profile and interlabial gap with the upper incisor retraction. Increase in $\mathrm{Z}$ angle is significantly related to lower incisors retraction.

\section{Discussion}

The study of beauty and harmony of the facial profile has been central to the practice of orthodontics from its earliest days. ${ }^{11}$ Accurate prediction of changes in the soft tissue profile after orthodontic treatment is desired. There exists a wide variability between racial groups, but most of the studies regarding soft tissue profiles have been performed with White subjects. The aim of this study was to compare the soft tissue cephalometric effects on the facial profile in adult patients following first premolar extraction in North Indian population.

This study showed that there is change in the soft tissue profile of the adult patients after incisor retractions. This was in concordance to the study done by Drobocky and Smith ${ }^{8}$ in which $95 \%$ of patients with four premolars extraction had decreased lip protrusion, whereas the NLA increased by $5.2^{\circ}$, the upper lip retracted $3.4 \mathrm{~mm}$ to the $\mathrm{E}$ line, and the lower lip retracted $3.6 \mathrm{~mm}$ to the $\mathrm{E}$ line. In another study of white subjects conducted by Waldman, ${ }^{12}$ 1:3.8 ratio was found between upper lip retraction and incisor retraction. It was also found that maxillary incisor retraction caused upper lip retraction, increased lower lip length, and increased the NLA $^{13}$ whereas the mandibular incisor position determined lower lip position and shape. ${ }^{14}$

There were few studies that were not in accordance with this study. Hershey ${ }^{15}$ reported on the effect of incisor retraction on soft tissue profile changes in 36 postadolescent female patients. He concluded that neither the simple nor the multiple correlation coefficients obtained were clinically useful in predicting soft tissue response from incisor retraction. Similar findings were reported by Wisth ${ }^{16}$ who described lip morphology and treatment changes in two groups of boys. 
Table 1 Descriptive statistics and comparison of soft tissue cephalometric changes in pre- and posttreatment results

\begin{tabular}{|c|c|c|c|c|c|c|}
\hline \multirow[t]{2}{*}{ Parameters } & \multicolumn{2}{|c|}{ Pretreatment $(n=24)$} & \multicolumn{2}{|c|}{ Posttreatment $(n=24)$} & \multirow[t]{2}{*}{ Mean difference } & \multirow[t]{2}{*}{$p$-Value } \\
\hline & Mean & SD & Mean & SD & & \\
\hline \multicolumn{7}{|l|}{ Angular } \\
\hline NLA & 100 & 10.875 & 105.38 & 9.600 & 5.38 & $0.010^{\mathrm{a}}$ \\
\hline $\mathrm{H}$ angle & 21.58 & 4.652 & 18.46 & 4.139 & 3.13 & $0.0001^{\mathrm{a}}$ \\
\hline Z angle & 58.83 & 7.341 & 64.04 & 7.099 & 5.21 & $0.0001^{\mathrm{a}}$ \\
\hline Soft tissue profile & 24.96 & 7.515 & 23.42 & 6.213 & 1.54 & 0.146 \\
\hline Mentocervical angle & 117.25 & 8.955 & 119.46 & 6.086 & 2.21 & 0.198 \\
\hline Upper lip angle & 15.54 & 8.049 & 7.29 & 4.467 & 8.25 & $0.0001^{\mathrm{a}}$ \\
\hline \multicolumn{7}{|l|}{ Linear } \\
\hline Upper lip prominence & 9.75 & 4.416 & 8.21 & 4.324 & 1.54 & $0.001^{\mathrm{a}}$ \\
\hline Upper lip length & 17.67 & 2.665 & 18.88 & 2.346 & 1.21 & $0.001^{\mathrm{a}}$ \\
\hline Lower lip prominence & 7.88 & 3.012 & 6.58 & 2.812 & 1.29 & $0.001^{\mathrm{a}}$ \\
\hline Lower lip length & 36.46 & 3.476 & 38.00 & 3.162 & 1.54 & $0.004^{\mathrm{a}}$ \\
\hline E line to upper lip & -0.42 & 2.145 & -1.58 & 2.430 & 1.17 & $0.011^{\mathrm{b}}$ \\
\hline E line to lower lip & 1.79 & 3.189 & 0.17 & 2.390 & 1.63 & $0.001^{\mathrm{a}}$ \\
\hline Interlabial gap & 3.13 & 2.490 & 0.50 & 1.063 & 2.63 & $0.0001^{\mathrm{a}}$ \\
\hline Superior sulcus depth & 7.13 & 1.801 & 5.38 & 1.663 & 1.75 & $0.0001^{\mathrm{a}}$ \\
\hline Upper lip thickness & 12.13 & 1.727 & 11.79 & 1.817 & 0.33 & 0.363 \\
\hline Upper lip strain & 9.46 & 1.560 & 10.33 & 1.274 & 0.88 & $0.002^{\mathrm{a}}$ \\
\hline Lower sulcus depth & 4.25 & 1.152 & 4.00 & 1.103 & 0.25 & 0.299 \\
\hline $\begin{array}{l}\text { Soft tissue chin } \\
\text { thickness }\end{array}$ & 9.67 & 2.036 & 9.13 & 1.825 & 0.54 & $0.034^{\mathrm{b}}$ \\
\hline
\end{tabular}

Abbreviation: SD, standard deviation.

$a_{p}<0.001$ highly significant.

$\mathrm{b}_{p}<0.05$ significant.

He reported that the variability of the results was great and concluded that prediction of soft tissue changes in an individual case is impossible, particularly if the overjet is great. ${ }^{17}$

The results in this study showed NLA increased from $100^{\circ} \pm 10.78^{\circ}$ to $105.83^{\circ} \pm 9.60^{\circ}$, with a mean difference of $5.38^{\circ}(p<0.01)$. Nasiolabial angle is made up of both soft tissue (pronasale) and cartillaginous (columella) portion of the nose which continues to grow forward, along with the soft tissue of the upper lip. Hence, adult patients were selected so as to reduce the influence of growth on hard and soft tissue parameters. This finding is in favor of the study done by Kojo et al, ${ }^{7}$ Talass et al, ${ }^{13}$ and Sundareswaran and Vijayan. ${ }^{10}$

$\mathrm{H}$ angle was found to be decreased from $21.58^{\circ} \pm 4.65^{\circ}$ to $18.46^{\circ} \pm 4.14^{\circ}$ with a mean difference of $3.13^{\circ}(p<0.01) ; \mathrm{H}$ angle decreased due to retraction of incisors. This finding was found to be statistically insignificant. This finding is in accordance with the studies done by Kojo et al, ${ }^{6}$ Sundareswaran and Vijayan, ${ }^{10}$ and Kocadereli. ${ }^{11}$

$\mathrm{Z}$ angle increased from $58.83^{\circ} \pm 7.34^{\circ}$ to $64.04^{\circ} \pm 7.1^{\circ}$ with a mean difference of $5.21^{\circ}(p<0.01)$. This increase is associated with the retraction of lips when incisors are retracted. This finding was found to be significant only with lower incisor retraction. Kocadereli ${ }^{11}$ made a same conclusion showing an increase of $1.5^{\circ}$, whereas James ${ }^{18}$ concluded that $\mathrm{Z}$ angle increased by $6^{\circ}$ after treatment.
Soft tissue profile was decreased from $24.96^{\circ} \pm 7.51^{\circ}$ to $23.42^{\circ} \pm 6.21^{\circ}$, with a mean difference of $1.54^{\circ}$, which was found to be insignificant. When hard tissue and soft tissue parameters were compared and correlated, an increase in soft tissue profile following maxillary and mandibular incisor retraction was found to be statistically significant $(p<0.05)$. This finding is in favor of the studies which states that extractions lead to flatter facial profiles. ${ }^{8,11,18,19}$

Mentocervical angle was increased from $117.25^{\circ} \pm 8.95$ to $119.46^{\circ}$, with a mean difference of $2.21^{\circ}$. It was found that this correlation showed statistical significance only with the decreased angular measurement of UI-NA.

Upper lip angle was decreased from $15.54^{\circ} \pm 8.05^{\circ}$ to $7.29^{\circ} \pm 4.47^{\circ}$ with a mean difference of $8.25^{\circ}$. Decrease in the upper lip angle was found due to upper lip retraction. This finding was found to be significant. This finding is in favor of the studies which states that extractions lead to decreased upper lip angle. ${ }^{12,19,20}$

Upper lip and lower lip prominence were decreased from $9.75 \pm 4.42 \mathrm{~mm}$ to $8.21 \pm 4.32 \mathrm{~mm}$, with a mean difference of $1.54 \mathrm{~mm}$ and from $7.88 \pm 3.01 \mathrm{~mm}$ to $6.58 \pm 2.81 \mathrm{~mm}$, with a mean difference of $1.29 \mathrm{~mm}(p<0.01)$, respectively. This finding is in favor of the certain other studies that were done to establish the relationship between incisor retraction and lip prominence. ${ }^{8,10,12}$ 
Table 2 Pearson's correlation between hard and soft tissue changes

\begin{tabular}{|l|l|l|l|l|l|l|}
\hline & UI-SN & $\begin{array}{l}\text { UI-NA } \\
\text { (o) }\end{array}$ & UI-NA (mm) & IMPA & $\begin{array}{l}\text { LI-NB } \\
\text { (o) }\end{array}$ & LI-NB (mm) \\
\hline NLA & -0.360 & $-0.457^{\mathrm{a}}$ & -0.398 & -0.028 & -0.032 & $-0.452^{\mathrm{a}}$ \\
\hline H angle & 0.053 & -0.095 & -0.309 & 0.270 & 0.373 & 0.211 \\
\hline Z angle & -0.161 & -0.132 & -0.258 & $-0.502^{\mathrm{a}}$ & $-0.416^{\mathrm{a}}$ & $-0.431^{\mathrm{a}}$ \\
\hline Soft tissue profile & -0.284 & $-0.468^{\mathrm{a}}$ & $-0.411^{\mathrm{a}}$ & $0.495^{\mathrm{a}}$ & $.0526^{\mathrm{b}}$ & 0.070 \\
\hline Mentocervical angle & 0.081 & -0.120 & 0.038 & 0.015 & 0.041 & 0.195 \\
\hline Upper lip angle & 0.114 & 0.182 & 0.196 & -0.194 & -0.110 & -0.019 \\
\hline Upper lip prominence & 0.055 & -0.105 & -0.141 & -0.059 & -0.043 & -0.039 \\
\hline Upper lip length & -0.174 & -0.095 & -0.113 & 0.143 & 0.106 & 0.140 \\
\hline Lower lip prominence & 0.268 & 0.079 & 0.057 & 0.118 & 0.095 & 0.027 \\
\hline Lower lip length & -0.197 & -0.280 & -0.362 & 0.212 & 0.265 & 0.172 \\
\hline E line to upper lip & -0.236 & -0.038 & 0.099 & 0.254 & 0.194 & 0.216 \\
\hline E line to lower lip & 0.076 & 0.164 & 0.306 & 0.193 & 0.197 & 0.112 \\
\hline Interlabial gap & $0.454^{\mathrm{a}}$ & 0.278 & 0.198 & -0.001 & 0.073 & -0.011 \\
\hline Superior sulcus depth & 0.297 & 0.310 & 0.179 & -0.357 & -0.328 & -0.101 \\
\hline Upper lip thickness & 0.302 & 0.274 & 0.275 & 0.350 & 0.321 & 0.380 \\
\hline Upper lip strain & 0.059 & -0.071 & -0.139 & -0.046 & 0.043 & -0.259 \\
\hline Lower sulcus depth & 0.020 & -0.053 & -0.143 & -0.182 & -0.189 & -0.288 \\
\hline $\begin{array}{l}\text { Soft tissue chin } \\
\text { thickness }\end{array}$ & 0.069 & 0.021 & -0.099 & 0.006 & 0.065 & -0.087 \\
\hline
\end{tabular}

${ }^{a}$ Correlation is significant at the 0.05 level (2-tailed).

${ }^{\mathrm{b}}$ Correlation is significant at the 0.01 level (2-tailed).

Upper and lower lip lengths were increased from $17.67 \pm 2.66 \mathrm{~mm}$ to $18.88 \pm 2.35 \mathrm{~mm}$, with a mean a difference of $1.21 \mathrm{~mm}(p<0.01)$ and from $36.46 \pm 3.48 \mathrm{~mm}$ to $38 \pm 3.16 \mathrm{~mm}$, with a mean difference of $1.54 \mathrm{~mm}(p<0.01)$, respectively. The increase in lip lengths was found to be due to maxillary incisor retraction, but these findings were found to be insignificant. This result is in concordance with the studies done by Lamberton et al, ${ }^{21} \mathrm{Lew},{ }^{20}$ and Tan. ${ }^{22}$

Upper lip and lower lip to $\mathrm{E}$ line was decreased from $-0.42 \pm 2.14 \mathrm{~mm}$ to $-1.58 \pm 2.43 \mathrm{~mm}$ and from $1.79 \pm 3.19 \mathrm{~mm}$ to $0.17 \pm 2.39 \mathrm{~mm}$, respectively. These findings were found to be statistically significant. Murai ${ }^{23}$ reported that the treatment goal for adult maxillary protrusion patients was $-0.7 \mathrm{~mm}$ for the $\mathrm{Ls}$ to $\mathrm{E}$ line, and $0.1 \mathrm{~mm}$ for the $\mathrm{Li}$ to $\mathrm{E}$ line. As a result of our research, the upper lip was slightly more retrusive but the lower lip was almost at the ideal value. ${ }^{7}$ This finding is in concordance with the various other studies. ${ }^{7,8,11,17}$

The interlabial gap decreased from $3.13 \pm 2.49 \mathrm{~mm}$ to $0.50 \pm 1.06 \mathrm{~mm}$ with a mean difference of $2.63 \mathrm{~mm}(p<0.01)$ following retraction of the incisors. As the incisors are retracted, the everted upper and lower lips move toward each other leading to reduction in interlabial gap suggesting an improvement in lip competence. The finding is in concordance to the various other studies, ${ }^{10,11,13,14}$ which stated that incisor retraction leads to decrease in interlabial gap.

Burstone ${ }^{24,25}$ mentioned that the change in the position of the upper lip is also related to movement of the wraparound muscles and changes in the lower lip. Since the lower lip often touches the maxillary incisor, its position can be influenced by maxillary incisor retraction.

Superior and lower sulcus depths decreased from $7.13 \pm 1.80 \mathrm{~mm}$ to $5.38 \pm 1.66 \mathrm{~mm}$ and $4.25 \pm 1.15 \mathrm{~mm}$ to $4.00 \pm 1.10 \mathrm{~mm}$, respectively. A decrease in superior sulcus depth was found to be highly significant, whereas decrease in lower sulcus depth was statistically insignificant. When correlations were calculated, superior sulcus depth reduction was found due to maxillary incisor retraction. This finding is in favor of certain other studies that showed decreased sulcus depth with incisor retraction. ${ }^{7,8,14,20}$

Upper lip thickness was decreased from $12.13 \pm 1.73 \mathrm{~mm}$ to $11.79 \pm 1.82 \mathrm{~mm}$, with a mean decrease by $0.033 \mathrm{~mm}$. There was almost no change in the thickness. This finding is statistically insignificant. In a study done by Kojo et $\mathrm{al}^{7}$ and Sundareswaran and Vijayan, ${ }^{10}$ a similar finding was observed.

Soft tissue chin thickness decreased from $9.67 \pm 2.04$ to $9.13 \pm 1.82 \mathrm{~mm}$ with a mean difference of $0.54 \mathrm{~mm}(p<0.05)$ following incisor retraction. This finding is statistically insignificant and is in concordance with the study done by Singh ${ }^{26}$ in which it was concluded that the soft tissue chin thickness increased at all the points measured around the symphysis of the chin in both male and female patients after orthodontic correction. He also emphasized that changes in the basic position of the soft tissue nose and the soft tissue chin occur primarily as a function of growth, and there is little that an orthodontist can do to alter them. 
When treating Class II div1 malocclusions and Class I bimaxillary protrusion, it is assumed that the upper and lower lips will move back, while the nasolabial and labiomental angles increase as a result of the orthodontic retraction of the maxillary and mandibular incisors. In this study when we compared the hard tissue and soft tissue parameters using Pearson's correlation, retraction of the maxillary and mandibular incisors resulted in significant increase in NLA and soft tissue profile. A statistically significant increase in Z angle was observed in relation to lower incisor retraction and decreased interlabial gap that was statistically significant and was related to decrease in UI-SN $(p<0.05)$. Upper lip and lower lip to $\mathrm{E}$ line values were also reduced following retraction of the incisors, but this finding came out to be insignificant.

\section{Conclusion}

The following can be concluded from this study:

1. Significant increase in NLA, Z angle, upper lip length, lower lip length, and upper lip strain and significant decrease in $\mathrm{H}$ angle, upper lip angle, upper lip prominence, lower lip prominence, E line to upper lip and lower lip, interlabial gap, superior sulcus depth, and soft tissue chin thickness were observed when soft tissue parameters of pre- and posttreatment cephalograms were compared.

2. When the correlation between hard tissue parameters with soft tissue parameters was done, significant increase in NLA and $\mathrm{Z}$ angle and significant decrease in soft tissue profile and interlabial gap were observed.

On the basis of the results obtained from this study, the soft tissue profile can be altered following first premolar extractions with incisor retraction in Class II Div 1 malocclusion and Class I bi-maxillary proclination patients. Facial profile improvement can be enhanced by dentoalveolar and soft tissue retraction. Thereby, the main complaints of incisor and lip protrusion can be addressed following extraction treatment.

\section{Note}

This study was conducted at Bhojia Dental College and Hospital, Baddi, Himachal Pradesh, India.

\section{Conflict of Interest}

None declared.

\section{References}

1 Khan R, Sama PS. Smile designing. J Curr Res. 2018;10 (5):68989-68991

2 Mathis A, Laskin DM, Tüfekçi E, Caricco C, Lindauer SJ. Upper lip asymmetry during smiling: an analysis using three-dimensional images. Turk J Orthod 2018;31(2):32-36

3 Bass NM. Measurement of the profile angle and the aesthetic analysis of the facial profile. J Orthod 2003;30(1):3-9

4 Hicky JC, Zarb GA, Bolender CL, Boucher's Prosthodontic Treatment for Edentulous Patients. 9th edition. St. Louis: CV Mosby; 1985:373
5 Loi H, Nakata S, Nakisama A, Counts A. Effects of facial convexity on A-P lip position of the most favoured Japanese facial profiles. Angle Orthod 2005;75(3):326-332

6 Arnett GW, Jelic JS, Kim J, Cummings DR, Beress A, Worley CM, Chung B, Bergman R. Soft tissue cephalometric analysis: Diagnosis and treatment planning of dentofacial deformity. Am J Orthod Dentofac Orthop 1999;116:239253

7 Kojo M, Nishiura A, Yamagata S, Matsumoto N. Effect of premolar extractions on the softtissue profile of female adult Japanese orthodontics patients. J Osaka Dent Univ 2016;50(2):63-71

8 Drobocky OB, Smith RJ. Changes in facial profile during orthodontic treatment with extraction of four first premolars. Am J Orthod Dentofacial Orthop 1989;95(3):220-230

9 Jacobson A. A Textbook of Radiographic Cephalometry: From Basics to Videoimaging. Chicago: Quintessence Publishing Co Inc.; 1995

10 Sundareswaran S, Vijayan R. Profile changes following orthodontic treatment of class I bimaxillary protrusion in adult patients of Dravidian ethnicity: a prospective study. Indian. J Dent Res 2017;28(5):530-537

11 Kocadereli I. Changes in soft tissue profile after orthodontic treatment with and without extractions. Am J Orthod Dentofacial Orthop 2002;122(1):67-72

12 Waldman BH. Change in lip contour with maxillary incisor retraction. Angle Orthod 1982;52(2):129-134

13 Talass MF, Talass L, Baker RC. Soft-tissue profile changes resulting from retraction of maxillary incisors. Am J Orthod Dentofacial Orthop 1987;91(5):385-394

14 Roos N. Soft-tissue profile changes in class II treatment. Am J Orthod 1977;72(2):165-175

15 Hershey HG. Incisor tooth retraction and subsequent profile change in postadolescent female patients. Am J Orthod 1972;61(1):45-54

16 Wisth PJ. Soft tissue response to upper incisor retraction in boys. Br J Orthod 1974;1(5):199-204

17 Rains MD, Nanda R. Soft-tissue changes associated with maxillary incisor retraction. Am J Orthod 1982;81(6):481-488

18 James RD. A comparative study of facial profiles in extraction and nonextraction treatment. Am J Orthod Dentofacial Orthop 1998;114(3):265-276

19 Caplan MJ, Shivapuja PK. The effect of premolar extractions on the soft-tissue profile in adult African American females. Angle Orthod 1997;67(2):129-136

20 Lew K. Profile changes following orthodontic treatment of bimaxillary protrusion in adults with the Begg appliance. Eur J Orthod 1989;11(4):375-381

21 Lamberton CM, Reichart PA, Triratananimit P. Bimaxillary protrusion as a pathologic problem in the Thai. Am J Orthod 1980;77(3):320-329

22 Tan TJ. Profile changes following orthodontic correction of bimaxillary protrusion with a preadjusted edgewise appliance. Int J Adult Orthodon Orthognath Surg 1996;11(3):239-251

23 Murai S. [Downs analysis of maxillofacial changes after orthodontic treatment and correlation between hard and soft tissue profile changes.] J Tokyo Med Univ 1995; 53:7687

24 Burstone CJ. The integumental profile. Am J Orthod Dentofacial Orthop 1958;44:1-25

25 Burstone CJ. Lip posture and its significance in treatment planning. Am J Orthod 1967;53(4):262-284

26 Singh RN. Changes in the soft tissue chin after orthodontic treatment. Am J Orthod Dentofacial Orthop 1990;98(1):41-46 